part of the uterus through apertures arranged near the extremity of the tube, and readily flows out of the uterus through the longitudinal grooves. Being provided with four grooves, there are virtually four tubes for escape of fluid from the uterus. It should be filled with fluid before introduction in order to prevent entrance of air. I have employed this instrument with the greatest success in four cases where antiseptic irrigation of the interior of the uterus was necessary, and I consider that being of glass it possesses very great advantages over tubes of opaque material. This tube is, I need hardly say, only intended to be employed by the medical attendant. It may be suggested that in cases where intra-injection is employed, the prior irrigation of the vagina by means of the vaginal tube would be desirable.

Berkeley-square, $W$.

\section{CARDIAC DISEASE IN PREGNANCY AND} LABOUR

A CASE OF MITRAL STENOSIS COMPLICATING PREGNANCY AND LABOUR.

BY FREDERICK EDGE, M.B., B.Sc.LoND., F.R.C.S.ENG.

KNOWING the great interest which there is concerning cases of cardiac disease complicating pregnancy and labour, I think that $I$ shall only be doing my duty in recording the following case, and calling attention to the more salient features of it. Also in referring briefly to the causation of the symptoms, and to the best methods of avoiding and relieving the dangers arising in these cases.

Mrs. B- was a house-patient of St. Mary's Hospital, Manchester. She was thirty-four years of age, and this was her first pregnancy. She had been under treatment during the fourth and fifth months of pregnancy for cough, dyspnoea, and palpitation, and had been relieved to a great extent. She was just over seven months pregnant from her own reckoning when I examined her. She had the pinched, starved tacial appearance which a woman of weak health often presents in later months of pregnancy. Her face was covered with acne rosacea. She complained of pain in her chest and breathlessness, with palpitation, and her breathing was orthopnoic, not being able to lie down at night. Her family history was not good, and several members of her family died of phthisis. The patient had suffered from rheumatism many times, and from deprivation in food, clothes, and dwelling. She had been troubled for over a year with a cough and muco-purulent spit, and at times she spat blood. The cough had grown worse suddenly a week ago, and she had noticed a little blood in the sputum since. On inspection, the chest was thin and flat. The supra- and infra-clavicular regions were depressed, more so on the left side. The apices were dull on both sides, and tubular breathing, with moist sounds, was heard over them. However, I did not examine the lungs sufficiently carefully and systematically to be able to say more about them. The apex beat of the heart wasin the normal position. A thrill was felt at the apex running into the apex beat. On percussing out the heart the transverse dulness in the line of the fourth ribs was increased on the right side of the sternum. On anscultation the typical presystolic (auriculo-systolic) mur mur was heard at the apex, and also systolic and diastolic murmurs. The second sonnd was reduplicated and more accentuated in the pulmonary area than in aortic area. The pulse was irregular and intermittent at times. Her appetite was poor. She was passing a diminished amount of urine. She was sitting in a chair and could get about with little difficulty. She was put to bed and supported with pillows, finding that position more comfortable than lying down. A mixture containing iron and digitalis was given, also saline laxatives were ordered, and she had a cough mixture which she took when the cough was troublesome. She was under the care of a trained midwife. On the evening of July 2nd she was seized with labour pains, and the mid wife attended. The midwife reports nothing remarkable in the early stages of labour. The os was dilating gradually and was soft and pliable on examination. At noon on July 3rd she became suddenly worse, and the resident obstetric assistant-surgeon (Dr. Annacker) attended and I went with him. The patient was now extremely distressed, and she cried "Oh! my heart, my chest," indicating the organs which were least equal to the strain of the second stage of labour. The child presented by the breech, and delivery was hastened by traction on the groins first, with the finger and then with a blunt hook, and as the child was immature both femora were broken in the process of extraction, which had to be hastened as much as possible. Before the head was. born, the patient, who was supported by pillows and held herself in a sitting posture gasping and faint, suddenly collapsed and became cyanosed and insensible. The delivery of the head was at once effected. The placenta was brought away by hand immediately to cause bleeding. Brandy-and-milk enemata were given. Flannels wrung out in hot water and covered with turpentine were applied to præcordium. Artificial respiration was performed as one or two respiratory gasps were noticed afterthe heart impulse and pulse were lost. All pulsation in the cardiac region and in arteries having stopped, and there being no respiratory efforts, the case was considered hopeless, and further treatment was not tried. Unfortunately I did not obtain permission for a post-mortem. Thecondition of the patient before labour began was, in my opinion, as follows. The apices of both lungs were affected with tubercle, the left. apex more extensively (my incomplete examination does not permit me to say in what stage of disease). About ten days before labour some hæmorrhagic infarcts occurred. The heart muscle was weak and degenerating. The mitral value was stenosed. The left ventricle was not hyper. trophied nor dilated to an appreciable extent. The left. auricle and the right ventricle and auricle were dilated.

Dr. Berry Hart points out that in these cases the danger is in the third stage, and I quite agree with him when the second stage is quickly and easily passed, and the heart disease is not in an advanced condition. But as is seen in this. case, the second stage is most acutely dangerous and fatall when the disease is not compensated for and the strain is. severe, since it causes stoppage of the heart-an organ which, as we see in giving chloroform, is not easily started again when once stopped. During the second stage of labour the abdominal expulsive muscles coming into action, raise the intra-abdominal pressure by which the uterus, with other viscera, is compressed. Now during a pain: the uterus is contracted and retracted upon its contents thus the uterine and placental sinuses are emptied of their blood at this time by the two forces acting. together. The intra-abdominal pressure tends to drive all this blood and the visceral blood out of the abdominal cavity. At this same time the diaphragm has descended in its contraction, and thus a vacuum exists in the thoracic cavity, as in ordinary inspiration, only of greater power. Hence the blood expelled from the abdomen is sucked into the thoracic cavity, since there is no resistance offered, and there is a vis a fronte in addition. Here it overdistends the large veins and the right heart, and may be said to drown the heart, which is already overtaxed with the driving of blood into the overfull pulmonary system. There is another factor. The centre for uterine contractions and the uterus itself are excited by carbonic acid in the blood, so that the dangerous state of semi-asphyxia maintains one of the chief causes of overdistension of the heart by keeping ur the uterine contraction. And, in addition, the convulsions of asphyxia, as they affect the respiratory muscles, are chiefly inspiratory at first, and thus tend to keep up the thoracic engorgement.

I think that in these cases marriage should be forbidden notwithstanding any social position, careful nursing, and treatment, and against the "aspirations morales" of which Jaccoud speaks. The case is different when the patient is pregnant. Here I should like to see the opinions of some authorities as to the advisability of inducing abortion at the third month; for it seems to me that if this operation is allowable at all, there is the most urgent call for it in cases of pregnancy with mitral stenosis, since the mother is going on to a fearful risk of death if allowed to go to a period when the child should be viable, and in which the child more often dies than lives after birth. Dr. Herman ${ }^{1}$ asks why they should not induce premature labour instead of giving strophanthus \&c.; but I should like to ask, Why induce premature labour? Why not induce abortion at the third month? However, allowing that it is decided to let the case take its natural course, I think that the treatment given by Dr. Macdonald and Dr. Berry Hart is very good. The patient is to be kept at rest and digitalis or stro phanthus given to assist the cardiac muscle in its attempt at 
compensatory hypertrophy which is necessary in pregnancy, and especially in this case for the right ventricle and the left auricle. Chloroform should be given during labour, or better perhaps, chloroform should be used to anresthetise the patient, and then ether given to keep the patient under, since ether does not depress the cardiac muscle so much as chloroform. Labour should be hastened by forceps or turning. In the third stage of labour free hæmorrhage relieves the engorged vascular system. Ergot should not be given unless there is no cardiac embarrassment and the hæmorrhage is too free. If no bleeding take place from the uterus and the heart's action fail, cupping over the heart should be practised, and I think that wet cupping would give speedier relief than dry cupping. Venesection from the arm, or even from the external jugular vein, should be done in cases of extreme urgency. think that the question of venesection of the external jugular is worth consideration, and it has occurred to me that did these cases come within the province of the surgeon we should hear of this procedure not infrequently. With our recent knowledge of the contraction of muscle, and knowing that when the weight or tension on a muscle has exceeded a certain point the muscle becomes lengthened instead of shortening in its action or "contraction," it is easy to see the great effect which might be produced on the heart muscle by relieving it of too great tension at a critical moment, as might be done by section of the external jugular vein, and venesection from the arm would have a much less direct and immediate effect. The child was premature and was treated for the fractures, and union took place, but afterwards died of bad feeding and neglect which caused ulcerative stomatitis and general marasmus.

St. Mary's Hospital, Manchester.

\section{TROPHOPATHY IN THE FATTY AND FIBROID DEGENERATIONS. ${ }^{1}$ \\ BY EPHRAIM CUTTER, M.D., LL.D., AND \\ JOHN ASHBURTON CUTTER, M.D., \\ FORMERLY ATTENDING PHYSICIAN TO DISPENSARY No. 3 OF THE INTERNATIONAL MEDICAL MISSIONARY SOCIETY.}

THE animus of this contribution is the belief of the writers that trophopathy (trophos, food; pathos, disease) has more to do with the cause of the so-called incurable diseases than the profession gives credit to ; and to show that our belief is founded on facts, we will immediately proceed to the consideration of the subject in the concrete-to wit, the reading of some histories of patients that have been under our care.

CASE 1.-A little more than four years ago a gentleman brought to our office a friend, who appeared to the senior writer to be almost moribund; indeed, he feared that the man would die in the office. Examination showed the patient to be suffering from an enlarged heart, a fibroid liver, and Bright's disease of the kidneys ; the urine contained albumen, casts, and fatty epithelia. We will here make note that in our study of patients for the evidence of Bright's disease little care is paid whether the casts are fatty, hyaline, waxy, \&c. Amyloid bodies are usually found in the urine when the kidney is first breaking down. But we consider no case to be full-fledged Bright's disease till albumen, casts, and fatty epithelia are found. There may be any one of these three, or any two. It is a common matter to find such cases which are just hovering along the margin of health and disease, and yet not full-fledged, so to speak. This patient, desperate as his case was, went under the treatment to be further on described, and recovered, and would be here to-day for your examination if possible. His heart, liver, and kidneys are now doing healthy work.

CASE 2.-About one year before his death, America's greatest laryngologist, Dr. Louis Elsberg, came under the care of the senior writer. His case was one of Bright's disease, with all the signs, as before enumerated. He was placed on rigid diet, and would take no medicines. This regimen he followed out for months, and all of the morpho-

1 A joint paper read before the Section of Practice of Medicine, Materia Medica, and Physiology of the American Medical Association, at its fortieth annual meeting, 1889, by the junior writer. logical and chemical evidences of his disease disappeared from the urine. He was then allowed some latitude in his diet. The senior writer called one morning early at his office and found Dr. Elsberg at breakfast, eating freely of all the starches and sugars that were placed before him. It was said to him, "Elsberg, if you persist in this reckless diet, you will kill yourself." "The medical world knows how he died suddenly of pneumonia-perhaps Bright's disease of the lungs.

CASE 3.-About four years ago a millionaire was treated for two months for Bright's disease of the kidneys and lungs. At the expiration of that time, feeling too poor to continue under a pbysician's care, he undertook the direction of his own case, ate wrongly, overworked himself, and, while superintending some repairs in his house, was poisoned with sewer gas. The doctor was sent for again, but the grood work that had been done for him in the two months' treatment was thoroughly undone, and he died.

CASE 4,- In June, 1880, the senior writer called to see a primipara in a non-professional way. She was within three weeks of her expected confinement, and to his horror he found her bloated. On examination the urine proved to be heavily albuminous, and contained casts and fatty epithelia. She was placed on rigid diet, but labour came on in thirty-six hours, and she was easily delivered of her child, which weighed only three pounds and a half. The placenta was covered with numerons elevations, whieh, under the microscope, proved to be made up of plates of cholesterine. Two days after her confinement a steam fireengine came to the corner near the house in which she lived, and, having been fastened to a hydrant, commeneed to pump. The noise worried her; entreaties to the engineer to desist were of no avail, and the poor woman went into convulsions. The senior writer arrived soon afterwards. She was kept under the influence of ether, and was purged, but the convulsions did not cease till thirty-six hours had elapsed. She was placed on a diet of beef-tea; no medieine. Later on, broiled steaks were given her. The face was drawn to the side, and her brain was very weak. The regimen was persisted in till the pathological evidences were removed from the urine, and since this time her diet has been two-thirds animal and one-third vegetable food. She has borne two more children, both of whom are much more rugged than the first, and there have been no more convulsions.

CASE 5.-Mrs. - went on treatment about four years ago, and on thorough examination was found to be suffering from fibrous consumption, Bright's disease, and a small fibroid tumour of the womb, about the size of a man's fist. The evidences of Bright's disease disappeared; the fibroid tumour has gone; and we can say that she is cured of her fibrous consumption, if there is such a thing as a cure of a chronic disease. She is now passing through the change of life, and can by no means be called a thoroughly well woman, yet if she is here to-day, I think you will find, on talking with her, that she considers the diseased condition above enumerated as not troubling her now.

CASE 6. --Three years ago a young married woman came to our office and was found to be suffering from Bright's disease of the kidneys ; indeed, it is rare to find urine that contained as many casts and of all kinds as hers did. She was placed on treatment, and in one month's time the pathological evidences had nearly all disappeared. She persevered, and is to-day enjoying good health.

CASE 7.-The Rev. society, came under our care at about the same time as Case 6. He also had Bright's disease. He went on treatment, though keeping at his work. His loss of flesh and strength at first greatly disturbed his wife, and it was hard work to make her believe that he should be held to the plans. After three months he took a holiday in Maine, still pursuing the plans of diet and medication, and in the fall came back to work. This case may be called in progress. His occupation is a very laborious one, tiring to the mind and full of worry. At the present he is under the plan of two-thirds animal and one-third vegetable food, eating one kind of meat and one vegetable at a meal. On June 18th, 1889, his specimen presented no casts, no fatty epithelia, and but a trace of albumen. Yet he tells us that he has-never in his life worked so hard as the last month, and wonders that he holds on as well as he does.

CASE 8 (1877).-The senior writer saw in consultation a lady who was said to be dying of Bright's disease, and that the attending physicians wished blood to be transfused into 